\title{
Management of supratentorial recurrent low-grade glioma: A multidisciplinary experience in 35 adult patients
}

\author{
JULIEN SPITAELS ${ }^{1}$, DANIEL DEVRIENDT ${ }^{2}$, NILOUFAR SADEGHI ${ }^{3}$, SYLVIE LUCE $^{4}$, \\ OLIVIER DE WITTE ${ }^{1}$, SERGE GOLDMAN ${ }^{5}$, CHRISTIAN MÉLOT $^{6}$ and FLORENCE LEFRANC ${ }^{1}$ \\ ${ }^{1}$ Department of Neurosurgery, Hôpital Erasme, Université Libre de Bruxelles, 1070 Brussels; \\ ${ }^{2}$ Department of Radiotherapy, Institut Jules Bordet, 1000 Brussels; Departments of ${ }^{3}$ Radiology; ${ }^{4}$ Medical Oncology; \\ ${ }^{5}$ Nuclear Medicine and ${ }^{6}$ Emergency, Hôpital Erasme, Université Libre de Bruxelles, 1070 Brussels, Belgium
}

Received July 16, 2016; Accepted December 9, 2016

DOI: $10.3892 / 01.2017 .6543$

\begin{abstract}
The management of recurrent diffuse low-grade gliomas (LGGs) is controversial. In the present study, the multidisciplinary management of 35 patients with recurrent LGGs was retrospectively analyzed. Tumor progression or recurrence was defined by clinical, radiological and/or metabolic pejorative evolution. All patients were regularly followed up by a multidisciplinary neuro-oncological group at Hôpital Erasme. Patients with histologically confirmed supratentorial LGGs (7 astrocytoma, 22 oligodendrogliomas and 6 oligoastrocytomas) who had undergone surgery between August 2004 and November 2010 were included. A total of 3 patients exhibited no tumor progression (median follow-up (FU), 81 months; range, 68-108 months). Tumor recurrence occurred in the 32 remaining patients [progression-free survival (PFS), 26 months; range, 2-104 months]. In addition, 25/29 (86\%) patients who received surgery alone underwent reoperation at the time of tumor recurrence, and high-grade transformation occurred in 6 of these patients (24\%). Furthermore, $4 / 29(14 \%)$ patients were treated with adjuvant therapy alone (3 chemotherapy and 1 radiotherapy). In the 19 patients with no high-grade transformation at reintervention, 3 received adjuvant therapy and 16 were regularly followed up through multimodal imaging. The PFS time of the patients who underwent reoperation with close $\mathrm{FU}(\mathrm{n}=16)$ and for the patients receiving adjuvant therapy with or without surgery $(n=7)$ at first recurrence was 10 and 24 months $(\mathrm{P}=0.005)$, respectively. However, no significant difference was observed for overall survival $(\mathrm{P}=0.403)$. At the time of this study, 22 of the 35 patients included were alive following a median FU time of 109 months (range, 55-136). The results of the present study
\end{abstract}

Correspondence to: Dr Florence Lefranc, Department of Neurosurgery, Hôpital Erasme, Université Libre de Bruxelles, 808 Route de Lennik, 1070 Brussels, Belgium

E-mail: florence.lefranc@erasme.ulb.ac.be

Key words: chemotherapy, low-grade glioma, radiotherapy, tumor recurrence, surgery, temozolomide could change the multidisciplinary approach used into a more aggressive approach with adjuvant therapy, with or without surgery, for the treatment of a select subpopulation of patients with LGGs at the first instance of tumor recurrence.

\section{Introduction}

Glioma is one of the most common types of primary brain tumor in adults and represents $>50 \%$ of all brain tumor cases (1). Low-grade gliomas (LGGs) generally referred to the three most common histological subtypes of World Health Organization (WHO) 2007 grade II gliomas that occur in the cerebral cortex, diffuse astrocytoma, oligoastrocytoma and oligodendroglioma, and are not benign tumors (1). LGGs represent a heterogeneous group with a 2016 WHO classification that includes astrocytomas and oligodendrogliomas and specific molecular markers (1p/19q codeletion, IDH1/2 mutation, and histone H3-K27 M mutation) (2). LGGs are infiltrative and slow-growing. Following the surgical resection of an LGG, residual tumor cells at the periphery of the excised tumor core can give rise to a recurrent tumor, and their natural history often terminates with transformation into a high-grade glioma (1).

The treatment options for patients with infiltrating LGGs remain controversial and the prognosis of patients with LGGs vary. Patient prognosis and the optimal management of patients with LGGs depend on numerous factors, including the following: Karnofsky Performance Scale score; presence of preoperative neurological deficits; presence of seizures; tumor diameter; velocity of tumor diameter expansion; crossing of the midline of the brain; tumor contrast enhancement; histological type; and the expression of molecular markers (3-11). The therapeutic goals are aimed at improving overall survival (OS) and progression-free survival (PFS), in addition to minimizing morbidity and maximizing the quality of life of patients with LGGs. Evidence over the last 2 decades, from the European and American literature, has noted that the extent of resection in patients with LGGs is an important factor affecting OS (12-15). However, prospective controlled studies evaluating the role of surgery are lacking (14-16). Observation appears to be appropriate for selected patients, and the wait-and-see approach remains widely practiced and 
continues to be a controversial approach (16). Guidelines exist on the management of patients with LGGs, as outlined by the European Federation of Neurological Society and the European Association of Neuro-Oncology task force (17), however, the treatment of patients with newly diagnosed or suspected LGGs is a controversial area in neuro-oncology. Since numerous areas of controversy involve the management at recurrence or evolution (18), the present retrospective study analyzed the multidisciplinary management of adult patients with supratentorial recurrent LGGs.

\section{Patients and methods}

Patients. Retrospective analyses were performed on the follow-up (FU) care of 35 adult patients with histologically confirmed supratentorial LGGs (7 with astrocytoma, 22 with oligodendroglioma and 6 with oligoastrocytoma; WHO 2007 classification). Patients received their first surgery between August 2004 and November 2010, and were regularly followed up by a multidisciplinary neuro-oncological group at the Hôpital Erasme (Brussels, Belgium). Tumor recurrence/progression was defined through clinical, radiological and/or metabolic evolution. Metabolic assessments with positron emission tomography (PET) have previously been performed for the diagnosis and FU of patients with LGGs (19).

The present study was approved by the research ethics board of the Hôpital Erasme (ref Erasme P2016/231; Université Libre de Bruxelles, Brussels, Belgium). The clinical data collected included the following: Age, sex, clinical presentation, contrast enhancement at magnetic resonance imaging (MRI), MR perfusion, metabolic assessment using PET with C-11 methionine (Met), adjuvant therapies [external beam radiotherapy (EBRT) and chemotherapy] received, PFS time and OS time.

Statistical analysis. Continuous data are presented as the median and range. Categorical data are presented as numbers and percentages. The OS and PFS were calculated using non-parametric Kaplan-Meier estimates. All statistical analyses were performed using Statistix ${ }^{\mathcal{O}}$ software (version 9.0; Analytical Software, Tallahassee, FL, USA). P $<0.05$ was considered to indicate a statistically significant difference.

\section{Results}

In the present study, clinical data from 35 patients with histologically confirmed supratentorial LGGs (7 astrocytomas, 22 oligodendrogliomas and 6 oligoastrocytomas), who had surgery between August 2004 and November 2010, were included. Demographic data are shown in Table I.

In total, 3 patients exhibited no tumor progression [FU, 70 months; range, 68-97 months; age, 41 years old]. This non-recurrent population (median age, 41 years) was composed exclusively of oligodendrogliomas, including 2 with a $1 \mathrm{p} 19 \mathrm{q}$ codeletion (1 undetermined) (Fig. 1). All 3 patients underwent complete surgical resection of the LGG.

Tumor recurrence occurred in the 32 remaining patients with supratentorial LGGs (PFS, 23 months; range, 2-104) and included 3 patients at high-risk of tumor recurrence who received EBRT following surgery (PFS, 9 months; range,
Table I. Clinicopathological characteristics of patients with supratentorial recurrent low-grade glioma.

\begin{tabular}{|c|c|c|}
\hline $\begin{array}{l}\text { Clinicopathological } \\
\text { characteristic }\end{array}$ & $\begin{array}{c}\text { At } \\
\text { diagnosis }\end{array}$ & $\begin{array}{l}\text { At } \\
\text { recurrence }\end{array}$ \\
\hline Number of patients & 35 & 32 \\
\hline \multicolumn{3}{|l|}{ Sex, n } \\
\hline Male & 20 & 18 \\
\hline Female & 15 & 14 \\
\hline \multicolumn{3}{|l|}{ Age, years } \\
\hline Median & 37 & 39 \\
\hline Range & $18-78$ & $18-78$ \\
\hline \multicolumn{3}{|l|}{ Primary clinical presentation, $\mathrm{n}$} \\
\hline Epilepsy & 30 & 8 \\
\hline Headache & 3 & 3 \\
\hline Aphasia & 1 & 2 \\
\hline Hazard/asymptomatic & 1 & 16 \\
\hline Neurocognitive impairment & 0 & 2 \\
\hline Hemiparesis & 0 & 1 \\
\hline \multicolumn{3}{|l|}{ Contrast enhancement at MRI, $\mathrm{n}$} \\
\hline Yes & 12 & 16 \\
\hline No & 21 & 16 \\
\hline Unknown & 2 & 0 \\
\hline \multicolumn{3}{|l|}{ Perfusion with MRI, $\mathrm{n}$} \\
\hline Increased & 4 & 4 \\
\hline Decreased & 8 & 10 \\
\hline Unknown & 23 & 18 \\
\hline \multicolumn{3}{|l|}{ PET-Met metabolism, $\mathrm{n}$} \\
\hline Hyper & 28 & 30 \\
\hline Нуро & 1 & 2 \\
\hline Unknown & 6 & 0 \\
\hline \multicolumn{3}{|l|}{ Tumor size, $\mathrm{cm}^{3}$} \\
\hline Median & 53 & - \\
\hline Range & $24-86$ & - \\
\hline \multicolumn{3}{|l|}{ Surgery received, $\mathrm{n}$} \\
\hline Yes & 35 & 25 \\
\hline No & 0 & 7 \\
\hline \multicolumn{3}{|l|}{ Tumor subtype, $\mathrm{n}$} \\
\hline Astrocytoma & 7 & 2 \\
\hline Oligodendroglioma & 22 & 13 \\
\hline Oligoastrocytoma & 6 & 4 \\
\hline Anaplastic & 0 & 6 \\
\hline \multicolumn{3}{|l|}{ EBRT received, $\mathrm{n}$} \\
\hline Yes & $\begin{array}{l}3 \text { (following } \\
\text { surgery) }\end{array}$ & $\begin{array}{l}2 \text { (1 following } \\
\text { surgery, } 1 \\
\text { without surgery) }\end{array}$ \\
\hline No & 32 & 30 \\
\hline \multicolumn{3}{|l|}{ Chemotherapy received, $\mathrm{n}$} \\
\hline Yes & 0 & $\begin{array}{l}5 \text { (2 following } \\
\text { surgery, } 3 \\
\text { without surgery) }\end{array}$ \\
\hline No & 35 & 27 \\
\hline
\end{tabular}

EBRT, external beam radiotherapy; MRI, magnetic resonance imaging; PET, positron emission tomography; met, C-11 methionine.

5-75 months; Fig. 1). The 3 patients at high-risk of tumor recurrence (median age, 58 years) included 2 patients with 


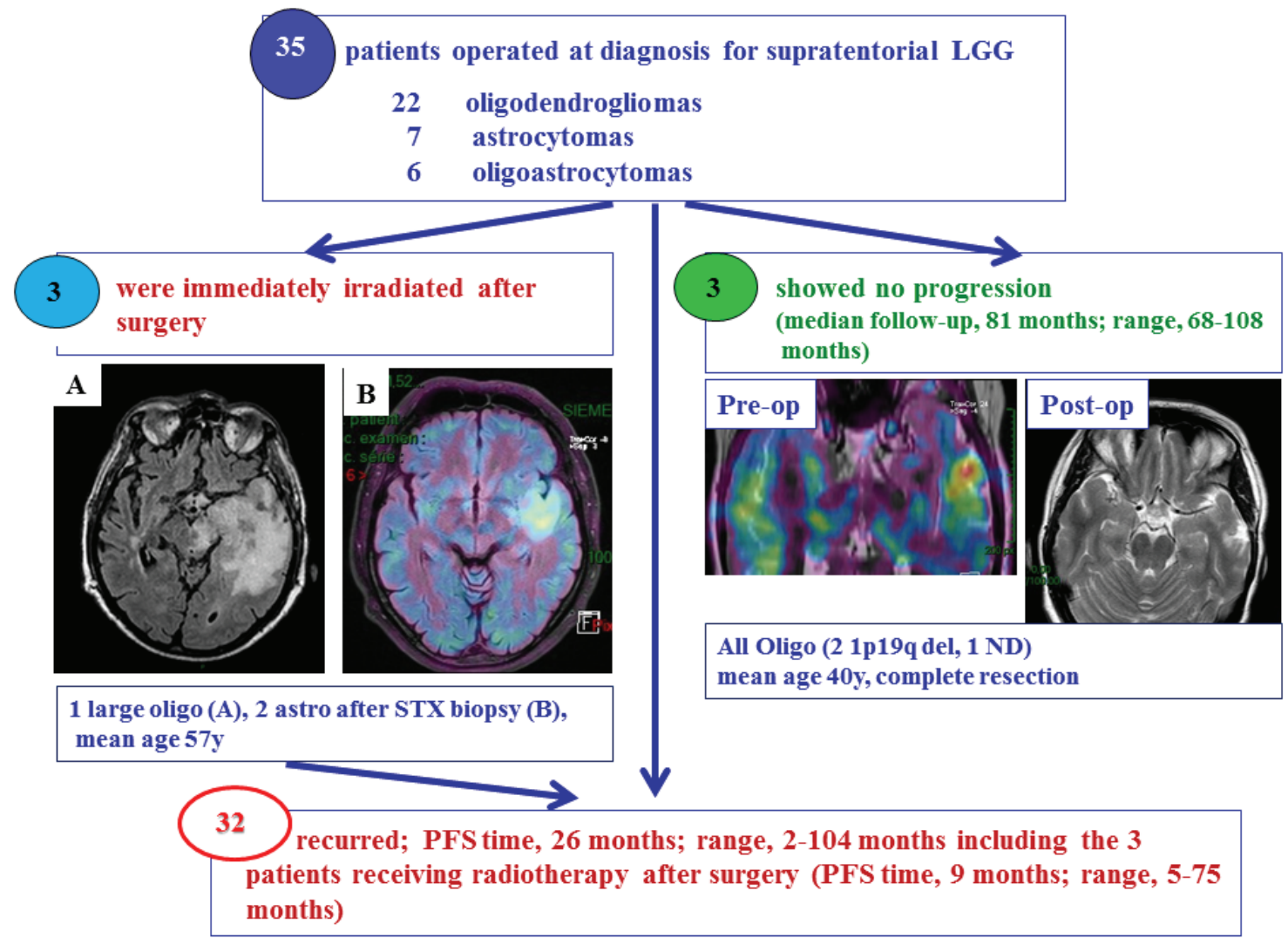

Figure 1. Patient selection. A total of 32/35 patients who underwent surgical resection for supratentorial LGGs exhibited tumor recurrence [PFS 26 months (range 2-104 months)] including the 3 patients receiving radiotherapy after surgery [PFS 9 months (range 5-75 months)], whereas 3 patients exhibited no tumor progression after median FU 81 months (range 68-108 months). All 3 patients with no tumor progression were diagnosed with oligodendroglioma and based on MRI and metabolic exams, these patients underwent complete resection. The pre-op image is a fusion image of the PET-Met with MRI, while the post-op image is the MRI following surgery. A total of 3 patients (mean age, 57 years) underwent irradiation therapy immediately after surgery. One was a large oligodendroglioma after patial resection in dominant left hemisphere (A) and 2 astrocytomas after biopsy with a hypermetabolic spot as illustrated in (B). LGG, low-grade glioma; MRI, magnetic resonance imaging; STX, stereotactic brain tumor biopsy; PFS, progress-free survival; oligo, oligodendroglioma; astro, astrocytoma; PET, positron emission tomography; met, C-11 methionine.

astrocytoma who underwent stereotactic biopsies and one patient with a large oligodendroglioma who underwent a partial surgery (Fig. 1).

The diagnosis of tumor recurrence was based on the following: MRI and metabolic evolution for 13; combined MRI, metabolic and clinical evolution for 11; metabolic and clinical evolution for 4; MRI and clinical evolution for 1; metabolic evolution alone for 2; and clinical evolution alone for 1 patient.

In total, 25 out of the $29(86 \%)$ patients who received surgery alone at diagnosis underwent reoperation at tumor recurrence (Fig. 2). As no definite position is available concerning reoperation at tumor recurrence [confirmed in a recent review by Nahed et al (18)], the strategy implemented was the proposal of a new resection once the multidisciplinary team had concluded that there was evident tumor recurrence in a brain region, for which the probability of post-surgical morbidity was low. This strategy is based on several arguments, including the following: Acquisition of histological and biological information on the recurrent tumor (with potential impact on further management), and the reduction of tumor load with a potential impact on current and future clinical signs, and on the probability and timing of future anaplastic transformation.
High-grade transformation of tumors occurred in 6/25 (24\%) patients who underwent reoperation, 5 of which were anaplastic tumors, in addition to 1 secary glioblastoma. All 6 patients received adjuvant therapy following reoperation and 3 patients were alive at the FU (FU time, 116 months; range, 114-127); however, 3 patients succumbed (OS, 36 months; range, 15-46 months).

A total of 4 patients diagnosed with tumor recurrence received adjuvant therapy without a second surgery $(4 / 29$, $14 \%$ ). Furthermore, 3 of these patients received chemotherapy, and 1 patient received EBRT (Fig. 2). In addition, $3 / 19(16 \%)$ patients diagnosed with recurrent LGGs following reoperation received adjuvant therapy; 2 of these patients received chemotherapy and 1 patient received EBRT. The 16 patients who did not receive adjuvant therapy were regularly followed via multimodal imaging (Fig. 2). The patients $(n=7)$ who received adjuvant therapy with $(n=3)$ or without $(n=4)$ a second surgery had a median age of 38 years and a large tumor volume (median diameter, $>61 \mathrm{~mm}$; range, 55-83 mm). All 5 patients who received chemotherapy were diagnosed with oligodendroglioma, including 3 patients with chromosome $1 \mathrm{p} 19 \mathrm{q}$ codeletion. The median PFS time prior to adjuvant therapy was 5 months for patients who received 


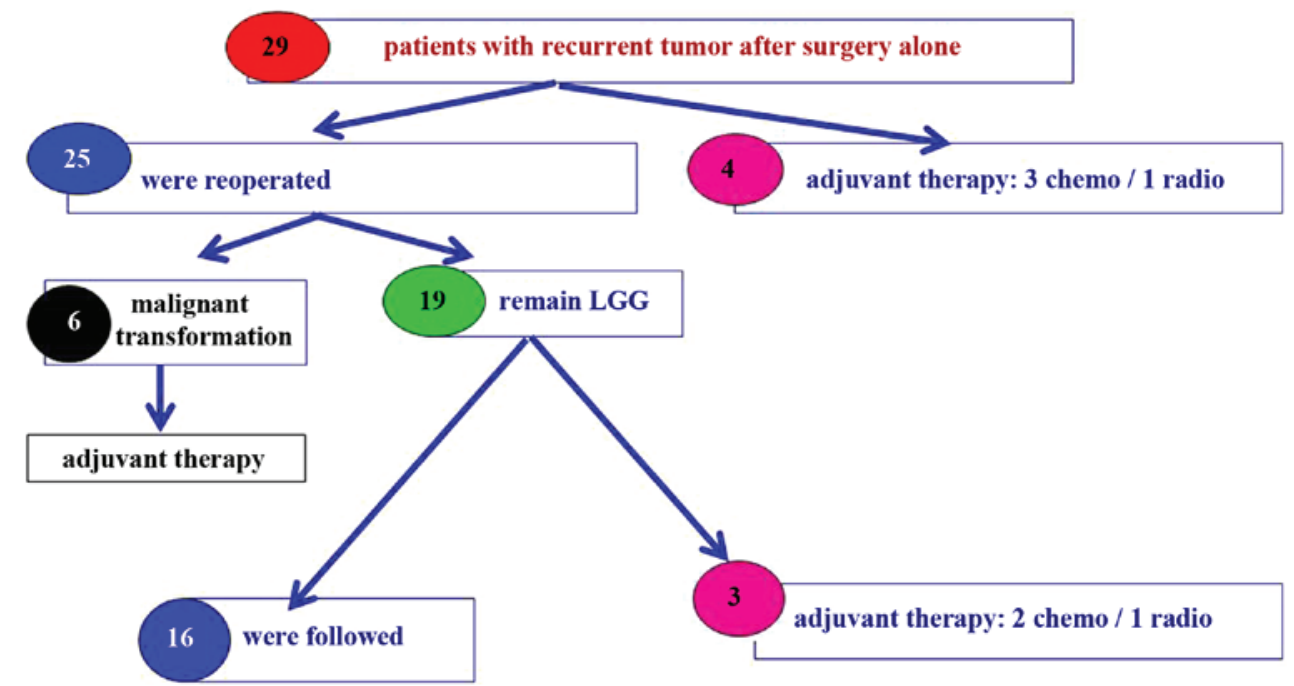

Figure 2. Dichotomy of the 29 patients with recurrent LGGs following surgery alone. LGG, low-grade glioma; chemo, chemotherapy; radio, radiotherapy.

A

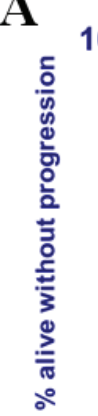

Number at risk

Group:1

Group: 2
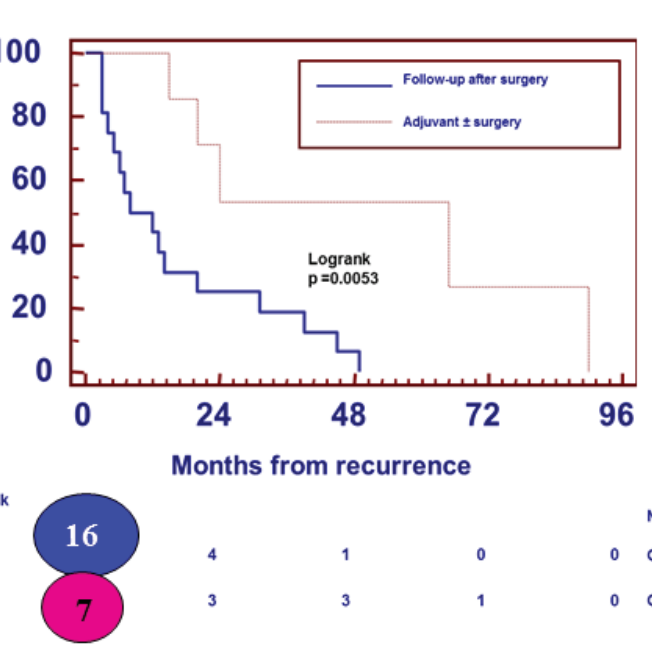

B

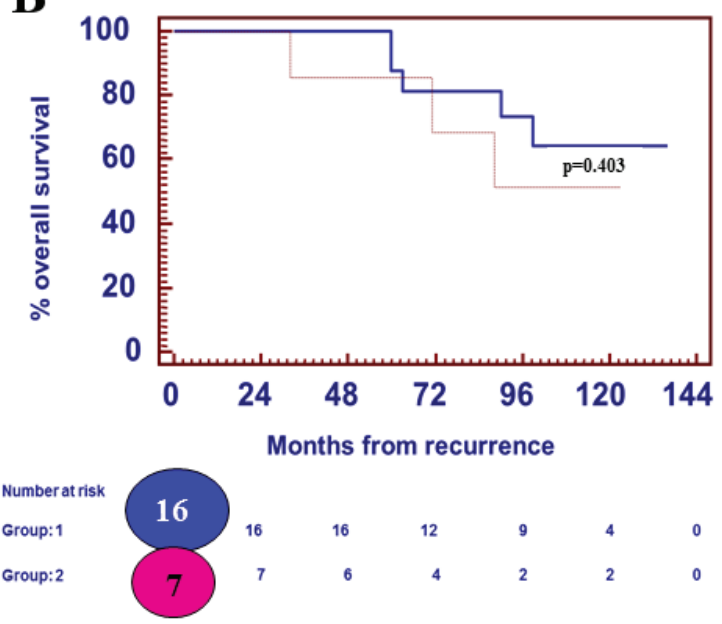

Figure 3. Patient outcomes. (A) Progression-free survival times for patients with low-grade gliomas who were reoperated on with a close FU (n=16) and for patients receiving adjuvant therapy with or without surgery $(\mathrm{n}=7)$ at first recurrence were 10 and 24 months, respectively $(\mathrm{P}=0.005)$. $(\mathrm{B}) \mathrm{No}$ significant difference was identified for overall survival $(\mathrm{P}=0.403)$.

radiotherapy and 23 months for patients who received chemotherapy.

A significant difference was identified between the PFS time for patients reoperated on with close FU $(n=16)$ and the PFS time for patients receiving adjuvant therapy with or without surgery $(n=7)$ at first recurrence, at 10 and 24 months, respectively ( $\mathrm{P}=0.005)$ (Fig. 3). No significant difference was observed for OS time ( $\mathrm{P}=0.403$; Fig. 3).

At the time of writing the present study, 22/35 of the included patients were alive following a median post-diagnosis FU time of 109 months (range, 55-136 months).

\section{Discussion}

In the present study, 3 patients (3/35) exhibited no tumor progression following the initial surgical resection. This non-recurrent population (mean age, 40 years) was exclusively composed of oligodendrogliomas, including 2 with $1 \mathrm{p} 19 \mathrm{q}$ codeletion after complete surgical resection. This indicates the importance of maintaining a good quality of life for patients with LGGs who experience long periods of stable disease (20).

In the present study, 3 patients who presented with a high risk of tumor recurrence (2 patients with astrocytoma who underwent stereotactic biopsy and 1 patient with a large oligodendroglioma who underwent partial surgery) received EBRT following surgery. The definition of low- vs. high-risk patients, including the cut-off age of 40 years, varies across studies $(4,9)$. To the best of our knowledge, there is no evidence demonstrating that immediate (post-operative) EBRT is advantageous in improving the OS time of patients with LGGs compared with deferred radiotherapy $(21,22)$. The PFS of patients with LGGs is lengthened; however, the optimal timing for receiving EBRT remains debatable $(21,22)$. Based on 19 years of experience, Youland et al (23) suggested that immediate postoperative EBRT should be implemented only for high-risk patients. It appears to be safe to delay EBRT in 
those patients in which it is possible to do so (23). A recent retrospective study revealed that upfront radiation was associated with an improvement in the PFS (time) of patients with LGGs, but also with a significantly decreased OS (time) and an increased rate of malignant degeneration (24). These findings indicate the limitations of retrospective studies with a small cohort and should be interpreted with caution.

The long-term FU of the Radiation Therapy Oncology Group 9802 clinical trial demonstrated a 5.5-year improvement in the median OS following EBRT+adjuvant procarbazine, CCNU and vincristine (PCV) chemotherapy compared with EBRT alone in patients with high-risk LGGs (25). While an analysis of the methods to determine the therapies best suited to individual patients according to tumor type and molecular profile is not currently available, EBRT $+\mathrm{PCV}$ remains the standard procedure for the treatment of patients with LGGs who require postsurgical adjuvant therapy (26). The optimal parameter for selecting patients to receive adjuvant PCV and the role of temozolomide (TMZ)-based chemotherapy remains unclear (27). The European Organization for the Research and Treatment of Cancer C2203 clinical trial investigated the effects of TMZ-based chemotherapy vs. EBRT in patients with LGGs. In this phase III clinical trial, patients were randomized to receive 12 cycles of TMZ-based chemotherapy or EBRT following stratification for genetic 1p loss. The preliminary results identified no significant difference between patients who received TMZ compared with patients who received EBRT (median PFS, 40 vs. 47 months) (28). Patients with 1p-intact LGGs showed a trend towards worse PFS with TMZ. The preliminary results of the Radiation Therapy Oncology Group 0424 clinical trial, a single-arm phase II study investigating the effects of concurrent and adjuvant TMZ with 54 Gy of EBRT in patients with LGGs suggested that TMZ improves survival in high-risk patients compared with a historical control group that received EBRT alone (29). Further studies investigating the effects of adjuvant TMZ compared with adjuvant PCV following EBRT are warranted. In addition, studies are required investigating the additional benefit of EBRT and chemotherapy agents in light of our new understanding of molecular markers.

In the present study, tumor recurrence occurred in 32/35 patients (PFS time, 26 months; range, 2-104 months), including 3 patients who received EBRT following surgery (PFS, 9 months; range, 5-75 months). Reoperation was performed on $25 / 29(86 \%)$ patients who received surgery alone. The data on the effect of reoperation on the OS and PFS times in patients with LGGs is limited. The results of a recent study on 52 patients with LGGs who underwent reoperation demonstrated that the extent of surgical re-resection remains the most efficient predictor of OS (24). A recent systematic review by Nahed et al (18) suggested that there is insufficient evidence to make specific recommendations for surgery at the time of tumor recurrence. However, reoperation appears to be an efficacious treatment for recurrent grade II glioma even in eloquent areas (30).

In the present study, 4 patients $(4 / 29,14 \%)$ received adjuvant therapy without a second surgery (3 chemotherapy and 1 EBRT), and only 3 received adjuvant therapy ( 2 chemotherapy and 1 EBRT) following the second surgery. All 5 patients who received chemotherapy were diagnosed with oligodendroglioma including 3 patients with chromosome $1 \mathrm{p} 19 \mathrm{q}$ codeletions. The majority of patients with recurrent LGGs following the second surgery were followed through MRI and PET (16/19 remaining LGGs at the second surgery).

Whether EBRT with second-line chemotherapy delivered at the time of relapse can provide the same survival advantage as first-line chemotherapy delivered with EBRT is yet unknown. Furthermore, long-term FU with investigations into the quality of life and cognition of patients with LGGs is warranted for this 'chronic' disease.

In the present study, malignant transformation was identified in $24 \%$ of the tumors following the second surgery (6/25 patients who did not received other intervening therapy). The incidence of malignant tumor transformation in several clinical series has ranged between 13 and $86 \%$. However, in the majority of these studies, malignant transformation has not been well reported. In addition, a number of these patients received EBRT and/or chemotherapy, which may have interfered with histological interpretation and confounded the natural progression of the LGG (31). The results of a study by Schmidt et al (31) revealed that $50 \%$ of patients with an initial diagnosis of infiltrative LGGs exhibited progression in terms of grade of malignancy by the time of reoperation.

In the present study, the PFS times of reoperated patients with close FU $(n=16)$ and patients receiving adjuvant therapy with or without surgery $(n=7)$ at first recurrence were 10 and 24 months, respectively. However, no significant difference was determined with regard to the OS time. This could be explained by the fact that patients who received adjuvant therapy were considered high-risk patients with an expected shorter survival time. In addition, adjuvant therapies, including EBRT with sublethal doses of irradiation close to the vicinity of the irradiated target, select a subpopulation of resistant and more aggressive cells, as demonstrated by Wild-Bode et al (32). It has not yet been established whether immediate post-radiation alkylating chemotherapy will possess the same benefit in patients previously treated with single modality alkylating chemotherapy, since previously treated tumors may have acquired resistance (25).

Since writing the present study, the majority of patients have remained alive $(22 / 35)$ following a median FU time of 109 months (range, 55-136 months). The outcome data from the LGG patients who underwent multiple surgeries continues to be assessed.

The limitations of this study were its retrospective nature and the lack of a uniform FU evaluation (such as volumetric analysis, perfusion and metabolic assessments) across a small cohort, and the fact that molecular profiles were not available for the entire cohort during the study period.

Based on retrospective studies suggesting that patients who undergo early, extensive and maximal tumor resections have an improved survival, the use of radical surgery is frequently supported (12-15,30). Prospective studies investigating the role of surgery are lacking, and the presumed benefit from extensive resection may be largely due to the patient selection process. A biopsy is performed to pathologically diagnose patients with LGGs in circumstances where the tumor location makes surgery difficult or impossible (16).

Gozé et al (6) reported that patients with a fast velocity of diametric expansion may be considered as 'high-risk', with an 
increased chance of early malignant transformation, particularly in those cases where a single biopsy has been performed due to the risk of undergrading. As there are common outcomes between LGGs and malignant gliomas, treatment modalities should be selected accordingly, and a 3-month FU period is preferred (33).

In conclusion, reoperation for the majority of patients with recurrent LGGs is preferred at the Hôpital Erasme, and is primarily motivated by the high level of malignant transformation observed. In addition, a second surgery aids in the accurate molecular characterization of LLGs. As a better understanding of the molecular biology of all types of brain tumor is gained, molecular signatures, longitudinal evaluation, and improved preclinical modeling and imaging technology may aid in the improvement of therapeutic strategies (34). The results of the present study may change the multidisciplinary approach into a more aggressive approach using adjuvant therapy with or without surgery for the treatment of a selected subpopulation of patients with LGGs at the instance of first recurrence.

As emphasized by Zadeh et al (16), the neuro-oncological community must continue to develop improved treatments for patients with LGGs, using further clinical trials and studies on better-targeted therapeutics. In addition, future directions should include the neurocognitive assessment of patients with LGGs with prolonged OS times.

\section{References}

1. Louis DN, Ohgaki H, Wiestler OD and Cavenee WK, (eds.): WHO Classification of Tumours of the Central Nervous System. IARC Press, Lyon, France: 2007.

2. Louis DN, Perry A, Reifenberger G, von Deimling A, Figarella-Branger D, Cavenee WK, Ohgaki H, Wiestler OD, Kleihues P and Ellison DW: The 2016 World Health Organization classification of tumors of the central nervous system: A summary. Acta Neuropathol 131: 803-820, 2016.

3. Chang EF, Smith JS, Chang SM, Lamborn KR, Prados MD, Butowski N, Barbaro NM, Parsa AT, Berger MS and McDermott MM: Preoperative prognostic classification system for hemispheric low-grade gliomas in adults. J Neurosurg 109: 817-824, 2008.

4. Daniels TB, Brown PD, Felten SJ, Wu W, Buckner JC, Arusell RM, Curran WJ, Abrams RA, Schiff D and Shaw EG: Validation of EORTC prognostic factors for adults with low-grade glioma: A report using intergroup 86-72-51. Int J Radiat Oncol Biol Phys 81: 218-224, 2011

5. Gorlia T, Wu W, Wang M, Baumert BG, Mehta M, Buckner JC, Shaw E, Brown P, Stupp R, Galanis E, et al: New validated prognostic models and prognostic calculators in patients with low-grade gliomas diagnosed by central pathology review: A pooled analysis of EORTC/RTOG/NCCTG phase III clinical trials. Neuro Oncol 15: 1568-1579, 2013.

6. Gozé C, Blonski M, Le Maistre G, Bauchet L, Dezamis E, Page P, Varlet P, Capelle L, Devaux B, Taillandier L, et al: Imaging growth and isocitrate dehydrogenase 1 mutation are independent predictors for diffuse low-grade gliomas. Neuro Oncol 16: 1100-1109, 2014.

7. Koekkoek JA, Dirven L, Heimans JJ, Postma TJ, Vos MJ, Reijneveld JC and Taphoorn MJ: Seizure reduction in a low-grade glioma: More than a beneficial side effect of temozolomide. J Neurol Neurosurg Psychiatry 86: 366-373, 2015.

8. Pallud J, Capelle L, Taillandier L, Fontaine D, Mandonnet E, Guillevin R, Bauchet L, Peruzzi P, Laigle-Donadey F, Kujas M, et al: Prognostic significance of imaging contrast enhancement for WHO grade II gliomas. Neuro Oncol 11: 176-182, 2009.

9. Pignatti F, van den Bent M, Curran D, Debruyne C, Sylvester R, Therasse P, Afra D, Cornu P, Bolla M, Vecht C, et al: Prognostic factors for survival in adult patients with cerebral low-grade glioma. J Clin Oncol 20: 2076-2084, 2002.
10. Sanson M, Marie Y, Paris S, Idbaih A, Laffaire J, Ducray F El Hallani S, Boisselier B, Mokhtari K, Hoang-Xuan K and Delattre JY: Isocitrate dehydrogenase 1 codon 132 mutation is an important prognostic biomarker in gliomas. J Clin Oncol 27: 4150-4154, 2009.

11. Weiler M and Wick W: Molecular predictors of outcome in low-grade glioma. Curr Opin Neurol 25: 767-773, 2012.

12. Berger MS, Deliganis AV, Dobbins J and Keles GE: The effect of extent of resection on recurrence in patients with low grade cerebral hemisphere gliomas. Cancer 74: 1784-1791, 1994.

13. Gousias K, Schramm J and Simon M: Extent of resection and survival in supratentorial infiltrative low-grade gliomas: Analysis of and adjustment for treatment bias. Acta Neurochir (Wien) 156 327-337, 2014.

14. Jakola AS, Myrmel KS, Kloster R, Torp SH, Lindal S, Unsgård G and Solheim O: Comparison of a strategy favoring early surgical resection vs a strategy favoring watchful waiting in low-grade gliomas. JAMA 308: 1881-1888, 2012

15. Smith JS, Chang EF, Lamborn KR, Chang SM, Prados MD, Cha S, Tihan T, Vandenberg S, McDermott MW and Berger MS: Role of extent of resection in the long-term outcome of low-grade hemispheric gliomas. J Clin Oncol 26: 1338-1345, 2008.

16. Zadeh G, Khan OH, Vogelbaum M and Schiff D: Much debated controversies of diffuse low-grade gliomas. Neuro Oncol 17: 323-326, 2015.

17. Soffietti R, Baumert BG, Bello L, von Deimling A, Duffau H, Frénay M, Grisold W, Grant R, Graus F, Hoang-Xuan K, et al: Guidelines on management of low-grade gliomas: Report of an EFNS-EANO task force. Eur J Neurol 17: 1124-1133, 2010.

18. Nahed BV, Redjal N, Brat DJ, Chi AS, Oh K, Batchelor TT, Ryken TC, Kalkanis SN and Olson JJ: Management of patients with recurrence of diffuse low grade glioma: A systematic review and evidence-based clinical practice guideline. J Neurooncol 125: 609-630, 2015.

19. Nihashi T, Dahabreh IJ and Terasawa T: Diagnostic accuracy of PET for recurrent glioma diagnosis: A meta-analysis. AJNR Am J Neuroradiol 34: 944-950, S1-S11, 2013.

20. Boele FW, Douw L, Reijneveld JC, Robben R, Taphoorn MJ, Aaronson NK, Heimans JJ and Klein M: Health-related quality of life in stable, long-term survivors of low-grade glioma. J Clin Oncol 33: 1023-1029, 2015.

21. Suneja G, Alonso-Basanta M, Lustig R, Lee JY and Bekelman JE: Postoperative radiation therapy for low-grade glioma: Patterns of care between 1998 and 2006. Cancer 118: 3735-3742, 2012.

22. van den Bent MJ, Afra D, de Witte O, Ben Hassel M, Schraub S, Hoang-Xuan K, Malmström PO, Collette L, Piérart M, Mirimanoff R, et al: Long-term efficacy of early versus delayed radiotherapy for low-grade astrocytoma and oligodendroglioma in adults: The EORTC 22845 randomised trial. Lancet 366: 985-990, 2005.

23. Youland RS, Brown PD, Giannini C, Parney IF, Uhm JH and Laack NN: Adult low-grade glioma: 19-year experience at a single institution. Am J Clin Oncol 36: 612-619, 2013.

24. Ramakrishna R, Hebb A, Barber J, Rostomily R and Silbergeld D: Outcomes in reoperated low-grade gliomas. Neurosurgery 77: 175-184, 2015.

25. Buckner JC, Shaw EG, Pugh SL, Chakravarti A, Gilbert MR, Barger GR, Coons S, Ricci P, Bullard D, Brown PD, et al: Radiation plus Procarbazine, CCNU, and vincristine in low-grade glioma. N Engl J Med 374: 1344-1355, 2016.

26. van den Bent MJ: Practice changing mature results of the RTOG study 9802: Another positive PCV trial makes adjuvant chemotherapy part of standard of care in low-grade glioma. Neuro Oncol 16: 1570-1574, 2014.

27. Laack NN, Sarkaria JN and Buckner JC: Radiation therapy oncology group 9802: Controversy or consensus in the treatment of newly diagnosed low-grade glioma? Semin Radiat Oncol 25: 197-202, 2015

28. Baumert B, Mason W, Ryan G, Bromberg JE, Van Den Bent MJ, Xuan KH,Brandes AA, Kantor G, Taphoom MJ, Hassel MB, et al: Temozolomide chemotherapy versus radiotherapy in molecularly characterized (1p loss) low-grade glioma: A randomized phase III intergroup study by the EORTC/NCIC-CTG/TROG/MRC-CTU (EORTC 22033-26033). J Clin Oncol 31 (Suppl), 2007.

29. Fisher BJ, Hu C, Macdonald DR, Lesser GJ, Coons SW, Brachman DG, Ryu S, Werner-Wasik M, Bahary JP, Liu J, et al: Phase 2 study of temozolomide-based chemoradiation therapy for high-risk low-grade gliomas: Preliminary results of radiation therapy oncology group 0424. Int J Radiat Oncol Biol Phys 91: 497-504, 2015. 
30. Martino J, Taillandier L, Moritz-Gasser S, Gatignol P and Duffau H: Re-operation is a safe and effective therapeutic strategy in recurrent WHO grade II gliomas within eloquent areas. Acta Neurochir (Wien) 151: 427-436, 2009.

31. Schmidt MH, Berger MS, Lamborn KR, Aldape K McDermott MW, Prados MD and Chang SM: Repeated operations for infiltrative low-grade gliomas without intervening therapy. J Neurosurg 98: 1165-1169, 2003.

32. Wild-Bode C, Weller M, Rimner A, Dichgans J and Wick W: Sublethal irradiation promotes migration and invasiveness of glioma cells: Implications for radiotherapy of human glioblastoma. Cancer Res 61: 2744-2750, 2001.
33. Pallud J, Blonski M, Mandonnet E, Audureau E, Fontaine D, Sanai N, Bauchet L, Peruzzi P, Frénay M, Colin P, et al: Velocity of tumor spontaneous expansion predicts long-term outcomes for diffuse low-grade gliomas. Neuro Oncol 15: 595-606, 2013.

34. Huse JT, Wallace M, Aldape KD, Berger MS, Bettegowda C, Brat DJ, Cahill DP, Cloughesy T, Haas-Kogan DA, Marra M, et al: Where are we now? And where are we going? A report from the Accelerate Brain Cancer Cure (ABC2) low-grade glioma research workshop. Neuro Oncol 16: 173-178, 2014. 